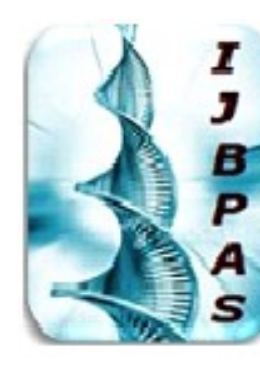

International Journal of Biology, Pharmaey and Allied Seiences (IJBPAS)

'A Bridge Betusen Caboratory and QRando'

WwW.ijbpas,com

\title{
IDENTIFY THE DISEASES INFECTED LEAF THROUGH DIFFERENT TRANSFORMS
}

\author{
RAJ II" AND BALA BK \\ Assistant Professor, Department of Computer Science and Engineering, K. Ramakrishnan \\ College of Engineering, Samayapuram, Trichy, Tamil Nadu, India \\ *Corresponding Author: E Mail: infantirudayam@gmail.com, kiranit2010@gmail.com \\ Received $9^{\text {th }}$ Oct. 2019; Revised $7^{\text {th }}$ Nov. 2019; Accepted $8^{\text {th }}$ Dec. 2019; Available online $1^{\text {st }}$ March 2020 \\ https://doi.org/10.31032/IJBPAS/2020/9.3.4987
}

\section{ABSTRACT}

Green environment is necessary in the present modern world and everyone interested in the same to customize the green environment as well to strengthen the agriculture process the system which deals with the leaf sample from that diagnose the disease affected leaf in earlier stage and save the agriculture as well as the green environment which act as an aid for the farmers and garden interested persons. To support for the above process identification of disease affected leaf in the earlier stage through analyze of different transforms for that best transform identify and applied for the system to give better result.

Keywords: Leaf, wavelet Transform, Discrete Fourier Transform, Fourier Transform,

\section{Haar Transform}

\section{INTRODUCTION}

The leaf sample will be analyze through different transforms from that process identification disease affected leaf to save the leaf as well as agriculture process will be easy and this particular system deals with 4 different types of transforms namely wavelet Transform, Discrete Fourier Transform, Fourier Transform, Haar Transform. The major transforms will be analyzed with result which give better result will be taken into the account. To analyze the result totally three parameter will be taken 
into the account namely time, FAR \& FRR for this system [1-2].

\section{MATERIALS AND METHODS}

The system initially has and leaf sample as input and feature has been extracted from the leaf image and features like color, shape and edge taken into the account for the process of the system. Then, apply the 4 major transforms with 3 major parameters like time, FAR \& FRR from that justify the better transform is shown in Figure 1[4].

From the Figure 2 and Figure 3 Shows the normal as well as disease affected leaf structure and feature will be extracted from the leaf of both normal as well as disease affected leaf for the better identification in earlier stage [6-7].

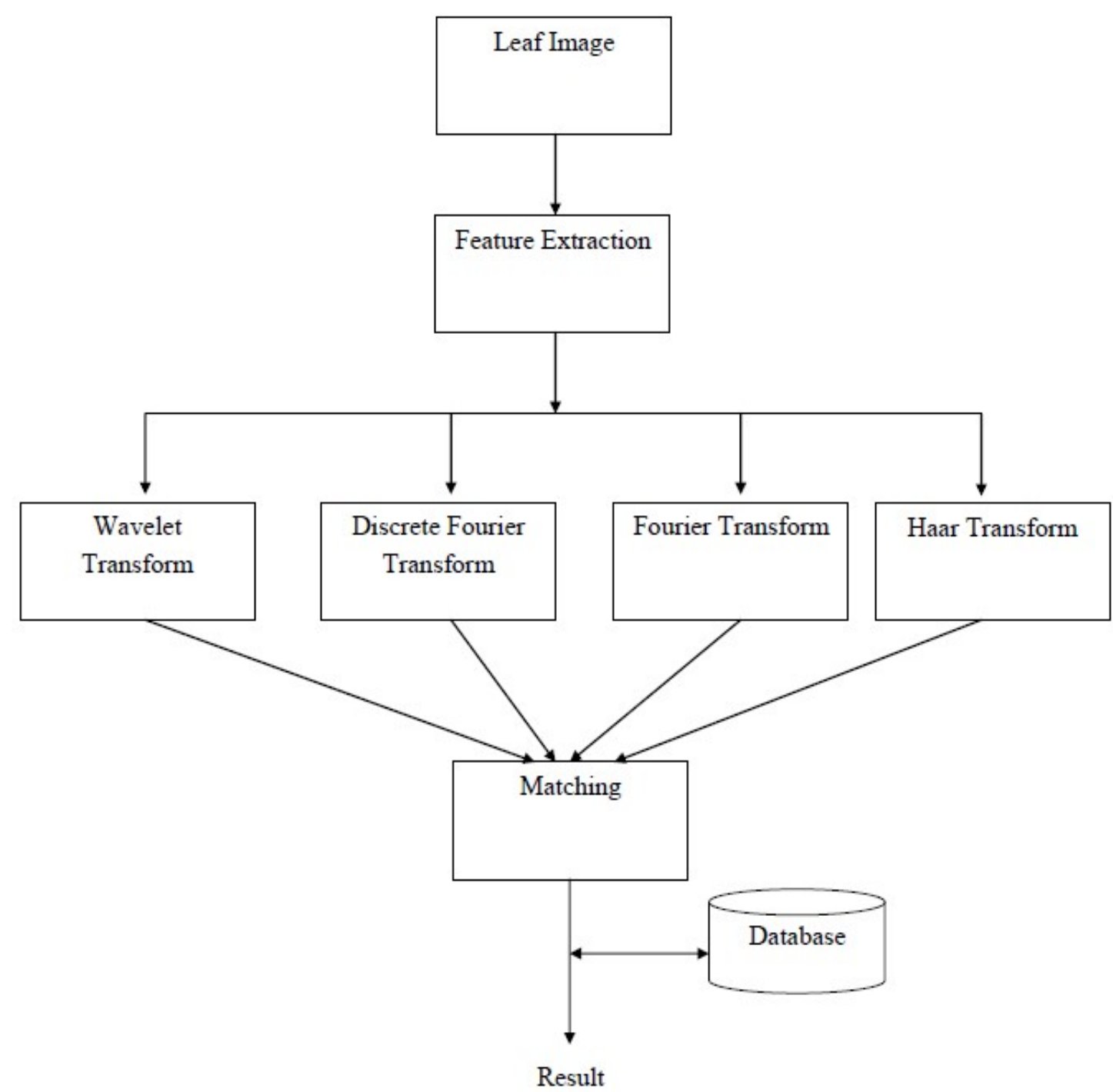

Figure 1: Basic Flow of the System 


\section{IMPLEMENTATION}

The system has totally 109 images taken into the account 57 different types of normal leaf taken and 52 disease affected leaf taken into the system as input for the feature extraction process. The feature extraction from the normal and abnormal leaf has color, edge and shape taken into the account for the implementation process is shown in Figure 4 \& Figure 5 [3].

In Figure 4 \& Figure 5 sample processed image available and likewise remaining the entire leaf feature extracted and 4 major transforms were applied and the Table $1 \&$ Table 2 Shows the result performance of the system with effective result [5].

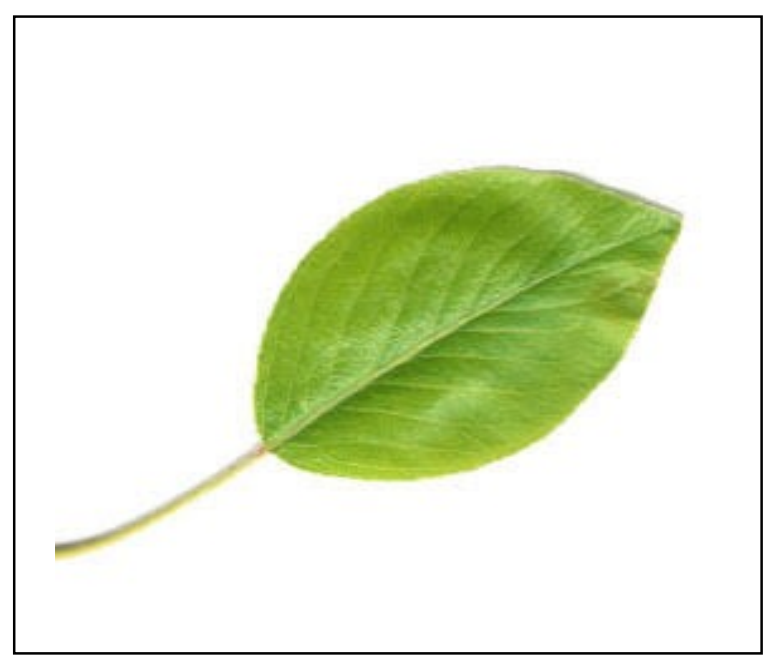

Figure 2: Normal Leaf

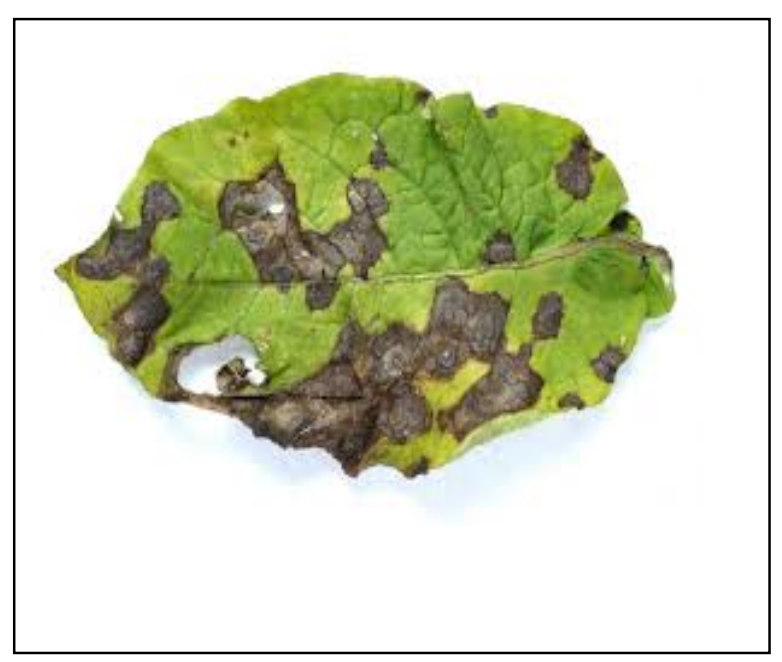

Figure 3: Disease Affected Leaf 


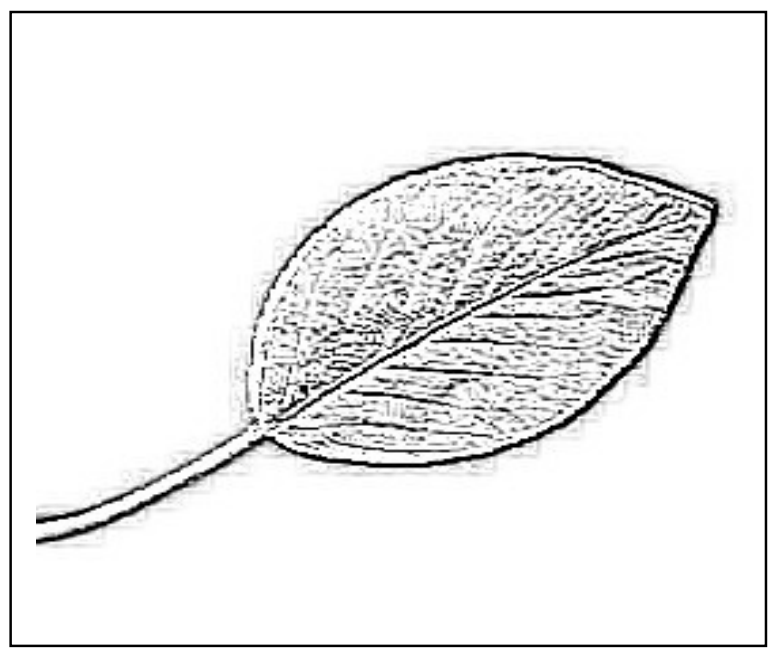

Figure 4: Processed Normal Leaf

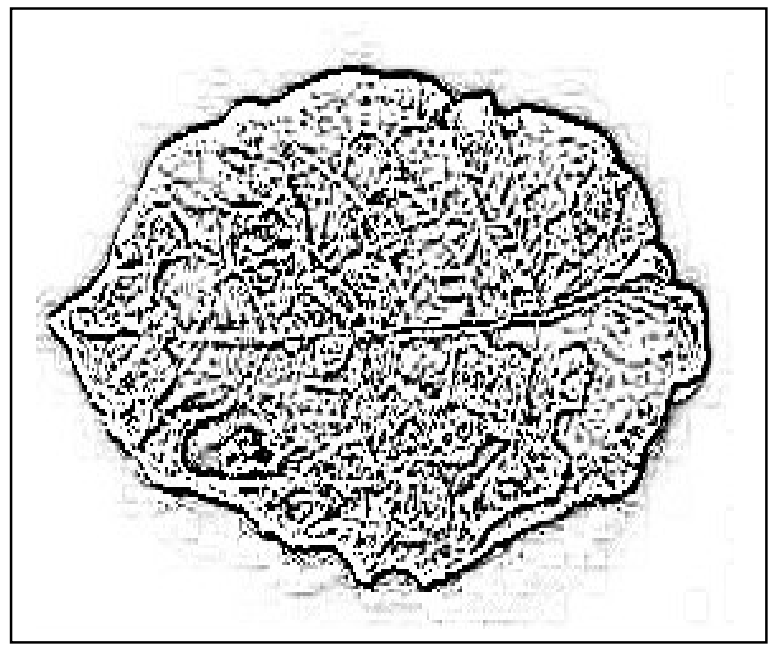

Figure 5: Processed Affected Leaf

Table 1: Result Analyze of Normal Leaf

\begin{tabular}{|c|c|c|c|c|}
\hline S. No & Transforms & Time $(\mathbf{s})$ & FAR (\%) & FRR (\%) \\
\hline 1. & Wavelet Transform & $\mathbf{0 . 0 1}$ & $\mathbf{1 0 0}$ & $\mathbf{1 0 0}$ \\
\hline 2. & Discrete Fourier Transform & $\mathbf{0 . 0 1}$ & $\mathbf{9 8 . 2 5}$ & $\mathbf{9 8 . 2 5}$ \\
\hline 3. & Fourier Transform & $\mathbf{0 . 0 2}$ & $\mathbf{9 8 . 2 5}$ & $\mathbf{9 8 . 2 5}$ \\
\hline 4. & Haar Transform & $\mathbf{0 . 0 2}$ & $\mathbf{9 8 . 2 5}$ & $\mathbf{9 8 . 2 5}$ \\
\hline
\end{tabular}

Table 2: Result Analyze of Affected Leaf

\begin{tabular}{|c|c|c|c|c|}
\hline S. No & Transforms & Time (s) & FAR (\%) & FRR (\%) \\
\hline 1. & Wavelet Transform & $\mathbf{0 . 0 1}$ & $\mathbf{9 8 . 2 5}$ & $\mathbf{1 0 0}$ \\
\hline 2. & Discrete Fourier Transform & $\mathbf{0 . 0 2}$ & $\mathbf{9 8 . 2 5}$ & $\mathbf{9 8 . 2 5}$ \\
\hline 3. & Fourier Transform & $\mathbf{0 . 0 2}$ & $\mathbf{9 8 . 2 5}$ & $\mathbf{9 8 . 2 5}$ \\
\hline 4. & Haar Transform & $\mathbf{0 . 0 1}$ & $\mathbf{9 8 . 2 5}$ & $\mathbf{9 8 . 2 5}$ \\
\hline
\end{tabular}




\section{CONCLUSION}

The system cleared explained difference between the normal leaf and affected leaf after that feature extraction taken from the leaf like color, shape \& edge those result will be processed by the 4 types of different transforms and implementation result strongly shown that wavelet transform is the best transform for the earlier identification of leaf for the system justify from the implementation.

\section{REFERENCE}

[1] B.Kiran Bala, S.Audithan, 'wavelet and curvelet analysis for the classification of microcalcifiaction using mammogram images', Publisher: IEEE, ISBN: 978-1-47997986-8, Page: 517-521.

[2] B.Kiran Bala, J.Lourdu Joanna, 'multi modal biometrics using cryptographic algorithm', european journal of academic essays, ISSN: 2183 1904, Vol 1 Issue 1, February 2014.

[3] B.Kiran Bala, 'a novel approach to identify the micro calcification images', Journal of chemical and pharmaceutical sciences, JCHPS Special Issue 2: February 2017, Page 190-192.
[4] B.Kiran Bala, 'a novel approach to generate a key for cryptographic algorithm', journal of chemical and pharmaceutical sciences, JCHPS Special Issue 2: February 2017, Page 229-231.

[5] B.Kiran Bala, R.Sasi Kumar, "a novel method of cultivation of different varieties of tomato without using soil", Bioscience Biotechnology Research Communications, Vol.10, Issues.4, PP 802-804

[6] Kiran Bala B, Audithan S, Kannan G, Raja, K, 'Frequency Domain Approaches For Breast Cancer Diagnosis', Australian Journal of Basic and Applied Sciences, Vol. 10, No. 2, pp. 93-96, 2016.

[7] R.Sasikumar, B.Kiran Bala, "Identification of Cancer from the Mammogram Images by using Frequency Domain Approaches", International Journal of Chem. Tech Research, Vol.10, No.5, 2017, PP 615-618. 